
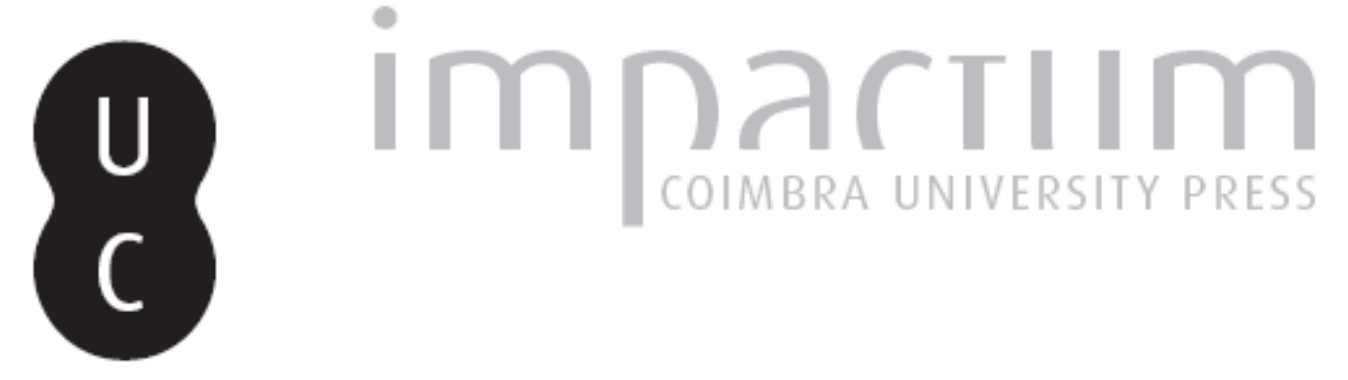

\title{
O atendimento policial em casos de violência conjugal
}

\author{
Autor(es): $\quad$ Marinho, L.; Matos, E.; Magalhães, T.
}

Publicado por: Imprensa da Universidade de Coimbra

URL persistente:

URl:http://hdl.handle.net/10316.2/33209

DOI:

DOI:http://dx.doi.org/10.14195/1647-8630_21_3

Accessed : $\quad$ 26-Apr-2023 02:58:24

A navegação consulta e descarregamento dos títulos inseridos nas Bibliotecas Digitais UC Digitalis, UC Pombalina e UC Impactum, pressupõem a aceitação plena e sem reservas dos Termos e Condições de Uso destas Bibliotecas Digitais, disponíveis em https://digitalis.uc.pt/pt-pt/termos.

Conforme exposto nos referidos Termos e Condições de Uso, o descarregamento de títulos de acesso restrito requer uma licença válida de autorização devendo o utilizador aceder ao(s) documento(s) a partir de um endereço de IP da instituição detentora da supramencionada licença.

Ao utilizador é apenas permitido o descarregamento para uso pessoal, pelo que o emprego do(s) título(s) descarregado(s) para outro fim, designadamente comercial, carece de autorização do respetivo autor ou editor da obra.

Na medida em que todas as obras da UC Digitalis se encontram protegidas pelo Código do Direito de Autor e Direitos Conexos e demais legislação aplicável, toda a cópia, parcial ou total, deste documento, nos casos em que é legalmente admitida, deverá conter ou fazer-se acompanhar por este aviso.

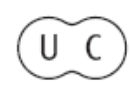




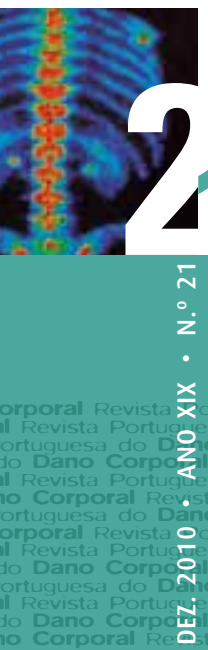

REVISTA PORTUGUESA

do

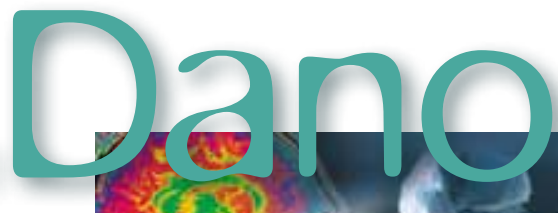

$\dot{z}$

$\dot{x}$

$\frac{x}{x}$

o. corporal Corporal Revista Portuguesa do Dano Corporal

Z

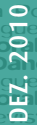

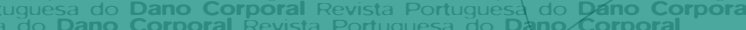

Revista Portuguesa do Dano Corporal Revista Rortuguesa do Dano Corporal

Sa do Dano Corporal Revista Portuguesa do Dano Corporal Revista Portuguesł do Dano Corporal

Portuguesa do Dano Corporal Revista portuguesta do Dano Corporal 


\title{
0 atendimento policial em casos de violência conjugal
}

\author{
L. Marinho ${ }^{1}$, E. Matos², T. Magalhães ${ }^{2-5}$
}

\section{Introdução}

$\mathrm{O}$ abuso conjugal refere-se aos comportamentos violentos perpetrados no contexto das relações de intimidade (formais ou informais). Apesar deste tipo de comportamentos ser praticado desde sempre, apenas nas últimas décadas sobre eles recaiu a atenção da opinião pública e uma penalização legal explícita.

Trata-se de um problema que afecta as famílias de todas as classes sociais e grupos culturais ${ }^{(1)}$, com consequências extremamente negativas para a vítima, para todo o agregado familiar e para a sociedade em geral. Além das implicações a nível da saúde física e mental que o abuso implica para as vítimas, as crianças que vivem num ambiente de violência, sendo testemunhas directas dos factos, manifestam também as graves consequências desta vitimização ${ }^{(7)}$.

No entanto, a violência conjugal ainda se encontra envolta numa cortina de silêncio, sendo escassas as estatísticas existentes devido à dificuldade das vítimas revelarem o abuso. Isto deve-se a questões culturais, que as levam a subvalorizar estes comportamentos, a resignarem-se perante eles e a terem vergonha e medo de enfrentar todo o processo a que conduziria a revelação ${ }^{(13)}$. Medo, sobretudo pelo risco de retaliação e das perdas associadas às suas dependências económicas e emocionais ${ }^{(13)}$, acabando muitas vezes por se envolverem num processo crescente de culpabilização, humilhação e degradação pessoal ${ }^{(16)}$. Por outro lado, estudos mais antigos referem a tradicional relutância da Polícia em intervir nestes casos ("entre marido e

\footnotetext{
Polícia de Segurança Pública

Instituto de Ciências Biomédicas Abel Salazar da Universidade do Porto

Faculdade de Medicina da Universidade do Porto

Delegação do Norte do Instituto Nacional de Medicina Legal, I.P.

CENCIFOR - Centro de Ciências Forenses, Portugal
} 
mulher ninguém meta a colher"), e dos Tribunais em condená-los ${ }^{(2)}$, a par com a própria sociedade, que tem manifestado uma tolerância implícita ao comportamento abusivo ${ }^{(10 ; 12)}$, por interiorização de uma ideologia que legitimava a repressão física como atributo do marido ${ }^{(2)}$.

As forças de segurança são muitas vezes a primeira entidade a ser solicitada ou mesmo procurada nos casos de violência conjugal sobre a mulher, pelo que o tipo de atendimento que a esta é prestado constitui um momento muito importante para a sua efectiva protecção e início do processo de reabilitação. Por outro lado, um mau atendimento pode ser causa de vitimização secundária, agravando-se as consequências de todo este processo ${ }^{(3)}$.

O presente estudo tem como objectivo avaliar a satisfação das mulheres vítimas de violência conjugal relativamente ao atendimento policial, tendo em vista identificar os problemas que necessitam de ser ultrapassados para garantir uma maior qualidade desse atendimento.

\section{Material e métodos}

Analisou-se uma amostra de mulheres vítimas de violência conjugal, que denunciaram a agressão numa Esquadra da PSP do Porto, no ano de 2005, e que foram observadas na Delegação do Norte do Instituto Nacional de Medicina Legal (INML) para exame pericial $(n=120)$. Os critérios de inclusão foram: (i) ser vítima de violência na relação conjugal ou equiparada; (ii) ser do sexo feminino; (iii) ter idade igual ou superior a 16 anos (idade legal para contraír matrimónio - artigo $1601^{\circ}$, alínea a) do Código Civil -, e para apresentação da queixa - artigo $113^{\circ}$, n. ${ }^{\circ} 3$ do Código Penal); (iv) ter havido atendimento policial por elementos afectos a uma Esquadra do Comando Metropolitano da PSP do Porto; (v) ter havido exame pericial na Delegação Norte do INML.

Procedeu-se à construção de um inquérito por questionário, de heteroaplicação, apenas com perguntas fechadas, composto por quatro partes: (I) a primeira relativa à caracterização demográfica da vítima e do suspeito abusador; (II) a segunda, à caracterização do abuso; (III) a terceira à denúncia policial; (IV) a quarta, à caracterização do atendimento policial. O questionário foi aplicado sempre pela mesma pessoa, na Delegação Norte do INML, após obtenção do necessário consentimento informado por parte das vítimas.

A análise estatística foi efectuada utilizando como software o programa SPSS (Statistical Package for Social Science), versão de 12.0 for Windows. Para a análise da relação entre as variáveis usou-se o teste Qui quadrado de Pearson, aplicando-se a simulação de Monte Carlo quando as células apresentavam uma frequência inferior a 5 em mais de $20 \%{ }^{(18)}$, e um nível de significância de $5 \%$. 


\section{Resultados}

A população estudada foi composta por mulheres com uma idade média de 38 anos ( $\mathrm{SD}=9.72$, Min=19, $\mathrm{Max}=65)$, casadas $(62.5 \%)$, tendo como habilitações literárias o ensino básico (55\%) e exercendo uma actividade profissional (73.3\%) com baixo grau de diferenciação (77.3\%). A maioria (96.7\%) tinha filhos, os quais, em $92.5 \%$ dos casos, presenciaram as cenas de violência.

Quanto ao suspeito abusador, a idade média foi de 41 anos ( $\mathrm{SD}=9.99$, Mín=20, Max=68), casados (63.3\%), com baixo nível de escolaridade (55.8\% com ensino básico) e 69.2\% exercendo uma profissão de baixo grau de diferenciação $(80.7 \%)$.

A duração da relação entre os membros do casal, até à apresentação da primeira denúncia, variou entre 1 e 44 anos, com uma média de 15 anos $(\mathrm{SD}=10.28)$, sendo superior a 10 anos em $62.5 \%$ dos casos (Tabela 1).

As mulheres referiam considerar-se vítimas concomitantemente de abuso físico e psicológico $(\mathrm{n}=118 ; 98.3 \%)$, sendo o abuso psicológico ou físico isolados quase inexistente $(\mathrm{n}=2)$, abusos estes que se iniciaram entre o $1 .^{\circ}$ e o $5 .^{\circ}$ ano de vida em comum em $59.2 \%$ dos casos. $\mathrm{O}$ abuso sexual foi revelado por $38.3 \%$ das mulheres $(n=46)$, importando contudo realçar que à pergunta directa sobre eventual abuso sexual responderam afirmativamente apenas 5\%; os restantes casos foram detectados após explicação às inquiridas quanto ao tipo de práticas que poderiam configurar um abuso sexual.

Como abuso psicológico, $98.3 \%$ das vítimas referiram ter sofrido insultos e/ou humilhações, $72.9 \%$ ameaças, $55.1 \%$ acusações infundadas de infidelidade e $31.4 \%$ serem alvo de permanente controlo ("com quem fala", "com quem sai", "para onde vai").

Quanto ao mecanismo do abuso físico, 99.2\% descreveram bofetadas, murros ou pontapés, 33.9\% objectos contundentes (e.g. vassouras, jarras, paus), $10.2 \%$ objectos cortantes (facas ou navalhas) e $8.3 \%$ referiram ter sofrido tentativa de esganadura.

Sobre o abuso sexual, $82.6 \%$ informaram que foram obrigadas a manter práticas sexuais que consideram normais, mas contra a sua vontade, 13\% mediante violência física e/ou psicológica, sendo que 10.9\% tiveram que manter práticas que consideram aberrantes e contra a sua vontade.

Realce-se, ainda, que 45 mulheres identificaram outros tipos de abuso: $26.7 \%$ foram privadas das necessidades básicas (alimentação e sono); a 64.4\% o suspeito abusador destruiu-lhes bens de valor económico e a $15 \%$ bens de valor afectivo.

Durante uma média de 15 anos as vítimas não apresentaram queixa porque: (i) acreditavam que o agressor mudaria de atitude (69.2\%); (ii) sentiam 
vergonha de revelar o abuso (40\%); (iii) queriam tentar manter a família unida (28.3\%); (iv) receavam que o abusador se tornasse mais violento (20.8\%).

As razões que as conduziram à denúncia foram: (i) a forte violência da última agressão (54.2\%); (ii) a incapacidade de continuarem a suportar a situação (48.3\%); (iii) o desejo de se separarem (35.8\%). Mas a apresentação da denúncia foi considerada como um momento particularmente complexo e stressante, pelo que embora $56.7 \%$ das vítimas se tenham sentido confiantes e seguras ao fazê-lo à polícia, 50\% sentiram receio pelas possíveis consequências deste gesto.

A maioria das vítimas $(n=102)$ deslocou-se a uma Esquadra da PSP para denunciar a situação, mas em muitos casos, a Polícia foi accionada para o local onde ocorreu a agressão. As vítimas atendidas no interior da esquadra em $86.3 \%$ dos casos sentiram-se satisfeitas com o atendimento prestado (Tabela 2).

O técnico de polícia que realizou o atendimento era, na sua quase totalidade, do género masculino (91.7\%). No entanto, para a maior parte das vítimas $(89.2 \%)$, o género do elemento policial que efectuou o atendimento foi indiferente.

A atitude do polícia foi sentida como positiva pelas vítimas, que consideraram o polícia atencioso, delicado e educado (80.4\%), interessado $(78.4 \%)$ e prestável $(65.8 \%)$, transmitindo-lhe segurança $(77.5 \%)$, compreensão e respeito $(76.5 \%)$. Apesar destes resultados, as vítimas entenderam que aqueles técnicos de polícia ainda necessitam de formação, tendo considerado a sua preparação para lidar com vítimas de violência conjugal pouca ou inexistente em 45.9\% dos casos (Tabela 3).

$\mathrm{Na}$ Esquadra, as mulheres foram atendidas, na sua maioria (89.2\%), no local de atendimento ao público em geral. $\mathrm{O}$ atendimento numa sala reservada ocorreu apenas em 10.8\% dos casos. Para além desse facto, as condições existentes na Esquadra não foram do agrado das vítimas (72.5\%), ora porque não havia uma cadeira para se sentarem $(20.2 \%)$, havia barulho $(24.5 \%)$, estavam presentes outras pessoas $(51 \%)$ ou a conversa era audível por terceiros (49\%). Consideraram, finalmente, que as condições de privacidade no atendimento estavam pouco ou nada garantidas em 35\% dos casos (Tabela 4).

\section{Discussão}

Tradicionalmente, os estudos referiam que a mulher vítima de violência conjugal era pobre, com pouca instrução e desempregada, embora se saiba já que a violência conjugal é uma realidade transversal a todas as classes sociais $^{(11 ; 21 ; 22)}$; o mesmo se diga em relação aos agressores ${ }^{(11)}$. Os resultados 
do presente estudo apontam também para o facto das vítimas serem mulheres sócio-culturalmente pouco favorecidas, mas tal apenas significa que este será o grupo que mais frequentemente procura a ajuda da polícia, não tendo outros recursos a que recorrer.

No que se refere aos abusos sofridos, é já ponto assente, na actualidade, que importa avaliar e valorar os seus diversos tipos, não estando apenas em causa os maus-tratos físicos, apesar de serem estes os geradores de evidências mais susceptíveis de facilitar a produção da sua prova ${ }^{(5)}$.

Vários estudos ${ }^{(8 ; 9 ; 10 ; 11 ; 12 ; 2)}$ referem que em cerca de 80\% das agressões conjugais, a violência psicológica acompanha a física, concluindo-se que o abuso físico raramente ocorre sem o abuso psicológico. O presente estudo vai de encontro a esses dados, constatando-se os dois tipos de abuso em $98.3 \%$.

Na violência psicológica prevalecem os insultos e as humilhações (98.3\%), as ameaças (72.9\%), acusações infundadas de infidelidade (55.1\%) e o isolamento (31.4\%), à semelhança de outros estudos ${ }^{(8 ; 1)}$. Na violência física, 99.2\% dos agressores utiliza a própria força (bofetadas, murros, pontapés, encontrões, puxões de cabelo), seguido de traumatismos com objectos contundentes $(33.9 \%)$ e o apertar o pescoço $(28.8 \%)^{(11)}$.

O uso de objectos cortantes, como facas e navalhas, é indicado por $10.2 \%$ das vítimas, um número superior ao referido no estudo de Lisboa, Barroso e Marteleira $^{(8)}$ que no INML do Porto constatou o uso dos referidos instrumentos em $4.8 \%$ dos casos. Ao contrário de outros estudos ${ }^{(8 ; 10)}$, nesta amostra não foi feita referência ao uso de armas de fogo por parte do agressor.

O abuso sexual na relação conjugal não tem sido sempre reconhecido, nem pelas próprias vítimas, até porque, supostamente, os votos do casamento obrigam à relação sexual, não se concebendo que o(a) outro(a) tenha o direito de dizer não(22; 23). À semelhança de Walker ${ }^{(22)}$, ao colocar-se às mulheres perguntas directas sobre a sua vida sexual com o abusador, sem utilizar o termo abuso, mas integrando nas questões comportamentos que o identificam, aquelas responderam afirmativamente a questões que retratam a existência de abuso sexual. Deste modo, os iniciais 5\% à pergunta directa "se sofria abuso sexual" passaram para 38.3\%, quando, sem referir esta expressão, se indagava se eram obrigadas a praticar relações sexuais pelo cônjuge/companheiro. A obrigação de manter relações sexuais contra a vontade da própria é o comportamento mais frequente deste tipo de abuso (82.6\%).

Relativamente ao momento da apresentação da queixa, verificou-se que a maioria $(56.7 \%)$ se sente confiante e segura ao fazê-la mas, simultaneamente, receosa com as consequências dessa queixa (50\%). Este resultado confirma a confiança que a Polícia transmite, apesar da insegurança da mulher em assumir o procedimento criminal ${ }^{(20)}$. 
As razões que conduzem ao reduzido número de queixas apresentadas pela vítima de violência conjugal prendem-se com questões sócio-culturais, já atrás referidas, mas, também, com aspectos situacionais e organizacionais, entre os quais, o tipo e condições do atendimento policial.

Assim, no que se refere a este atendimento, e apesar da opinião das mulheres ter sido francamente positiva - afirmando terem ficado satisfeitas com esse serviço, tanto no local da ocorrência (77.5\%), como na Esquadra $(86.3 \%)$-, ainda existem dificuldades, que urge ultrapassar, no que se refere às condições das instalações onde é realizado o atendimento, à própria actuação policial e às circunstâncias em que esse atendimento é efectuado.

$\mathrm{Na}$ perspectiva das mulheres, os aspectos menos positivos do atendimento policial são as condições das instalações policiais (83.1\%), a inexistência de elementos policiais especializados neste tipo de atendimento $(40.7 \%)$ e a falta de sensibilidade do técnico para lidar com a vítima (38.9\%), não sendo o género do elemento policial que efectua o atendimento relevante para $89.2 \%$ daquelas.

O problema da insuficiência das instalações das Esquadras está contudo a ser resolvido, através da criação de salas de atendimento à vítima, procurandose um ambiente que transmita segurança e tranquilidade, concedendo-lhe um tempo e um espaço onde possa exprimir aquilo que pensa e sente, sem temer qualquer juízo de valor ${ }^{(15)}$.

No que se refere à formação dos profissionais, e apesar da avaliação positiva feita pelas mulheres sobre a preparação dos agentes policiais (entendendo que estes estão bem ou razoavelmente preparados em 54.2\% dos casos), importa ter presente que estas vítimas apresentam uma importante ambivalência de sentimentos (se por um lado querem interromper o abuso, por outro, não querem romper os seus laços conjugais ${ }^{(20)}$ ), o que torna a sua abordagem particularmente complexa. Nessa medida, a formação dos técnicos que com elas trabalham constitui um passo fundamental e obrigatório, devendo ser incluída nos programas educativos assim que ingressam na função, e mantida através da formação contínua, ao longo da sua carreira ${ }^{(6)}$.

Esta formação irá também ser útil para ultrapassar as questões relacionadas com a falta de sensibilidade por parte dos técnicos para lidarem com esta problemática, aspecto que foi indicado por algumas mulheres. A este propósito, assinale-se que ainda existem polícias (4.2\%), cujas crenças culturais deixam transparecer o preconceito face à violência conjugal, fazendo a mulher sentir-se culpada pela violência, atitude que não se pode mais tolerar.

O presente estudo oferece-nos a visão do cidadão sobre o trabalho desenvolvido pela PSP do Porto no âmbito do atendimento à mulher vítima de violência conjugal. Deste modo, identificando os pontos menos positivos desse atendimento, permitirá definir estratégias para ultrapassar essas dificuldades. Mas desde já se pode afirmar que a PSP está no bom caminho, atendendo 
aos projectos em marcha, como a formação, melhoria das condições do local de atendimento e o estabelecimento de parcerias com instituições de apoio.

O contacto com as vítimas, aquando da administração do questionário, contribuiu para verificar que aquelas continuam a apontar a ineficácia da actuação policial como um grave problema. Contudo, culpam o sistema legislativo por isso e não o próprio polícia, verificando que este, perante o acto violento, se vê coarctado para agir, não porque não seja essa a sua vontade, mas porque a lei não permite que vá mais longe. Um caso frequente era a questão da entrada na residência, detenção do agressor e apreensão das armas que aquele possui.

Deste modo, além do trabalho a desenvolver pela PSP (formação dos seus elementos e melhoria das condições do local de atendimento), o Governo tem de, mais do que criar novas leis, promover as já existentes ${ }^{(17)}$. Assim, deve estabelecer medidas legítimas de intervenção policial e a sua tipificação quanto à sua natureza, pressupostos e objectivos, em conformidade com os interesses legítimos das vítimas de violência conjugal, no quadro de uma futura regulamentação da função policial.

\section{Conclusão}

Os resultados indicam que as mulheres demoram, em média, quinze anos a revelar o abuso de que são vítimas, apresentando-se muito fragilizadas e com profundos sentimentos de medo e de vergonha quando o fazem. Nesse momento, necessitam de apoio e compreensão por parte dos técnicos de polícia, o que nem sempre é garantido, sendo certo que as condições logísticas das polícias também não favorecem a criação do necessário clima de segurança e confiança.

Importa não esquecer que a abordagem pelo profissional que primeiro contacta com a vítima é fundamental para a sua recuperação ${ }^{(13)}$. Neste sentido, essa abordagem deve ser mínima, visando a recolha de informação suficiente e adequada para definir o tipo de intervenção a implementar, preocupando-se com a protecção da vítima, evitando procedimentos que contribuam para a sua vitimização secundária ${ }^{(3 ; 13)}$. Por isso, importa que esses profissionais sejam capazes de adequar a sua abordagem ao contexto da vitimização, à idade da vítima, bem como à percepção que esta tem do processo que sofreu, que sejam capazes de a ouvir, transmitindo-lhe confiança, sem que, nunca por nunca, emitam juízos de valor ${ }^{(13)}$.

Estando os técnicos cientes destas necessidades e limitações, tal como revelou um outro estudo efectuado ${ }^{\text {(cf. } 14),}$ teremos mais de metade do caminho percorrido para se poder garantir que a aposta na sua formação permitirá, num futuro próximo, contar com pessoas adequadamente preparadas para este tipo de atendimento. 
Tabela 1. Duração da relação (em anos) conjugal, até à apresentação da primeira queixa

\begin{tabular}{|l|c|c|}
\hline \multicolumn{1}{|c|}{ Duração da relação (anos) } & $\mathrm{n}$ & $\%$ \\
\hline 1 a 10 & 45 & 37.5 \\
\hline 11 a 20 & 44 & 36.7 \\
\hline 21 a 30 & 19 & 15.8 \\
\hline$>30$ & 12 & 10.0 \\
\hline TOTAL & 120 & 100 \\
\hline
\end{tabular}

Tabela 2. Distribuição das vítimas segundo o grau de satisfação com o atendimento policial prestado

\begin{tabular}{|l|c|c|}
\hline \multirow{2}{*}{ Satisfação com o atendimento policial } & \multicolumn{2}{c|}{ Na esquadra } \\
\cline { 2 - 3 } & $\mathrm{n}$ & $\%$ \\
\hline Muito satisfeita & 47 & 46.1 \\
\hline Satisfeita & 41 & 40.2 \\
\hline Insatisfeita & 10 & 9.8 \\
\hline Muito Insatisfeita & 4 & 3.9 \\
\hline TOTAL & 102 & 100 \\
\hline
\end{tabular}

Tabela 3. Preparação dos elementos policiais da PSP, perspectiva das mulheres vítimas

\begin{tabular}{|l|c|c|}
\hline \multicolumn{1}{|c|}{ Formação da polícia } & $\mathrm{n}$ & $\%$ \\
\hline Bem preparados & 30 & 25 \\
\hline Razoavelmente preparados & 35 & 29.2 \\
\hline Pouco preparados & 26 & 21.7 \\
\hline Nada preparados & 29 & 24.2 \\
\hline TOTAL & 120 & 100 \\
\hline
\end{tabular}

Tabela 4. Distribuição das vítimas segundo a garantia da privacidade no atendimento policial prestado

\begin{tabular}{|l|c|c|}
\hline \multicolumn{1}{|c|}{ Privacidade } & $\mathrm{n}$ & $\%$ \\
\hline Muito bem assegurada & 5 & 4.2 \\
\hline Bem assegurada & 48 & 40 \\
\hline Razoavelmente assegurada & 25 & 20.8 \\
\hline Pouco assegurada & 19 & 15.8 \\
\hline Nada assegurada & 23 & 19.2 \\
\hline TOTAL & 120 & 100 \\
\hline
\end{tabular}




\section{Referências bibliográficas}

(1) Alto Comissariado das Nações Unidas para os Direitos Humanos. Direitos Humanos e Aplicação da Lei. Manual de formação em direitos humanos para as forças policiais, Série de formação profissional, n. ${ }^{\circ}$ 05. Genebra: ONU; 2001.

(2) Beleza TP. A Mulher no Direito Penal. Lisboa: Edição da Comissão da Condição Feminina; 1984.

(3) Cotti A, Magalhães T, Pinto da Costa D, Matos E. Road traffic accidents and secondary victimisation: the role of law professionals. Medicine and Law 2004; 23(2):259-68.

(4) Direcção Geral da Saúde. Estratégias de combate à violência doméstica. Manual de recursos. Lisboa: Ministério da Saúde; 2003.

(5) Falcón MT. La violencia en casa, México: Paidos; 2001.

(6) Hanmer J, Radford J, Stanko E. Women Policing - International Perspectives. London: Routledge; 1989.

(7) Hoff LA. Violence against women and children: a portuguese and a international perspective. Espaço S, Revista de Educação Social 1999; 0:17 - 28.

(8) Lisboa M, Barroso Z, Marteleira J. O contexto social da violência contra as mulheres detectada nos Institutos de Medicina Legal. Síntese dos dados obtidos nos Institutos de Medicina Legal de Coimbra e Porto. Ditos e Escritos, n. ${ }^{\circ}$ 16. Lisboa: Comissão para a Igualdade e para os Direitos das Mulheres; 2003.

(9) Lisboa M, Vicente LB, Barroso Z. Saúde e violência contra as mulheres: estudo sobre as relações existentes entre a saúde das mulheres e as várias dimensões da violência de que tenham sido vítimas. Lisboa: Direcção Geral de Saúde; 2005.

(10) Lourenço N, Carvalho MJL. Viver sem medo. Conhecer a violência contra a mulher para a prevenir e combater. In: Faces de Eva - Estudos sobre a mulher, n. ${ }^{\circ}$ 6. Edições Colibri; 2001. pp. 9-26.

(11) Lourenço N, Lisboa M, Pais E. Violência contra as Mulheres. Cadernos Condição Feminina, n. ${ }^{\circ}$ 48. Lisboa: Comissão para a Igualdade e para os Direitos da Mulher; 1997.

(12) Matos M. Violência nas relações de intimidade: retratos e práticas. In: Polícia e Justiça, III Série. Coimbra: Coimbra Editora; 2004. pp. 105 - 121.

(13) Magalhães T. A vítima como objecto de intervenção médico-legal. Acta Médica Portuguesa 2005; 18:453-8.

(14) Marinho LPP. O atendimento policial à mulher vítima de violência conjugal. Estudo no Comando Metropolitano da Polícia de Segurança Pública do Porto. Tese de Mestrado em Ciências Forenses, Universidade do Porto; 2006.

(15) Mota SMC. CIDM - Comissão para a Igualdade e para os Direitos das Mulheres. In: Gonçalves RA, Machado C, Eds, Violência e vítimas de crime, vol. I - Adultos, 2. ${ }^{\mathrm{a}}$ ed. Coimbra: Quarteto Editora; 2003. pp. 302-17.

(16) Pais E. Rupturas violentas da conjugalidade. Homicídio conjugal em Portugal. Lisboa: Hugin Editores; 1998.

(17) Pais E. Violência Doméstica - perfil da prevenção e da intervenção em Portugal. In: Polícia e Justiça, III Série. Coimbra: Coimbra Editora; 2004. pp. 189-97.

(18) Pestana MH, Gageiro JN. Análise de dados para ciências sociais. A complementaridade do SPSS. Lisboa: Edições Sílabo; 2003. 
(19) Pereira A. Guia Prático de Utilização do SPSS. Análise de dados para ciências Sociais e Psicologia. Lisboa: Edições Sílabo; 2004.

(20) Soares RM. Violência conjugal. Lisboa: Escola Superior de Polícia; 1998.

(21) Walker LEA. The Battered Woman. New York: Harper \& Row Publishers; 1979.

(22) Walker LEA. The battered women syndrome. New York: Springer Publishing Company, Inc.; 2000.

(23) Wiehe VR. Understanding Family Violence. Treating and preventing partner, child, sibling and elder abuse. Thousands Oaks: Sage Publications; 1998.

Resumo: 0 atendimento policial em casos de violência conjugal

Até há pouco tempo atrás, a violência conjugal era considerada como um problema familiar no qual a Polícia, os serviços de saúde, as instâncias formais de controlo e os serviços sociais dificilmente intervinham. No entanto, em Portugal, desde 2000, este tipo de violência passou a corresponder a um crime público. Nestes casos, a vítima que se encontra num estado de grande fragilidade e perturbação emocional, procura com alguma frequência a Polícia, a qual constitui a first line enforcer. Será pois fundamental que estes profissionais sejam capazes de adoptar uma postura empática e apoiante, sabendo escutar activamente, durante todo o atendimento, sem limitar esse atendimento ao tradicional inquérito e à explicitação dos aspectos jurídicos e respectivos procedimentos legais. 0 presente trabalho tem como objectivo avaliar se a Polícia de Segurança Pública (PSP) presta a estas vítimas um atendimento que contribua para a sua efectiva protecção e reabilitação, evitando a sua vitimização secundária. Para tal, aplicou-se um questionário a uma amostra de 120 mulheres que referiam ser vítimas de violência conjugal e cujo atendimento foi realizado na PSP do Porto. Analisou-se o sentimento das vítimas face a esse atendimento, concluindo-se que a PSP necessitará de: a) continuar a apostar na formação especializada dos seus técnicos, com vista à adopção de procedimentos uniformes e de boas práticas na abordagem das vítimas; b) promover apoios especializados nos vários domínios da intervenção (psicológica, social e jurídica), designadamente através de parcerias e dinâmicas de actuação com as comunidades locais e as instituições de apoio; c) continuar a melhorar as condições do local de atendimento, criando salas de atendimento para as vítimas.

Palavras-chave: Vítima; violência conjugal; polícia.

Summary: The police reception in domestic violence cases

Some time ago, the couple life violence was considered as a familiar problem in which the Police, the Health Services, the Formal Instances and the Social Services hardly participate. However, in Portugal, since 2000, this kind of violence started to be seen as a public crime. In these cases, the victim that is always in a condition of great fragility and emotional disturbance/ disorder asks with some frequency for the police's help, that is the first line enforcer.

It will be essential that these professional people are able to adopt an empathic and supportive position, knowing how to listen to these victims actively during all the first reception, without limiting this first reception to the traditional inquiry and to the explanation of the juridical aspects and proper legal proceedings. 
This work has its main goal in evaluating if the PSP (Public Safety Police) is able to lend assistance to these victims in a way that contributes to their effective protection and rehabilitation, avoiding their secondary victimisation. To do so, it was held an inquiry to a sample of 120 women that said to be victims of couple life violence which contact was made by Oporto PSP. It was analysed the victims' feelings bearing in mind that reception, concluding that the PSP will need: a) continuing to bet in specialised training of their technicians, bearing in mind the adoption of regular proceedings and good practises in the victims' approaching; b) promoting specialised supports in the several domains of the intervention (psychological, social and legal), particularly through the partnerships and dynamics of performance with the local communities and the institutions of support; $c$ ) continuing to improve the conditions of the place where the reception takes place, by creating special rooms for the reception of the victims.

Key-words: Victim; couple/married life violence; police.

Résumé: L'accueil policier en cas de violence conjugal

Jusqu'à très peu de temps, la violence conjugal était considérée un problème familial au cours duquel la Police, les services de santé, les instances formelles de contrôle et les services sociaux difficilement intervenaient. Néanmoins, au Portugal, depuis 2000, ce type de violence ne dépend plus de plainte pour que la poursuite criminelle se fasse.

Dans ces cas, la victime se trouvant dans un état de grande fragilité et perturbation émotionnelle cherche souvent la Police pour un premier appui. Cela dit, les autorités policières sont ce que l'on peut désigner de first line enforcer.

Il est ainsi important que ces professionnels de sécurité soient empathiques envers ces victimes et soient capables de les soutenir, de les écouter activement pendant l'accueil, sans limiter cet accueil au questionnaire traditionnel qui s'effectue dans ces cas et aux explications des aspects juridiques. Cet ouvrage cherche à évaluer si la Police de Sécurité Publique (PSP) offre à ces victimes un accueil permettant une protection et une réhabilitation effectives, capables d'éviter de nouvelles victimisations. Pour cela, nous avons appliqué un questionnaire à un groupe de cent vingt (120) femmes victimes de violence conjugal et dont l'accueil a été réalisé par la PSP du Porto. L'analyse de ces questionnaires a démontrer que la PSP a besoins de : a) continué à parier sur la formation spécialisée de ces professionnels, ayant pour objectifs l'uniformisation des procédures au moment du contact avec les victimes ; b) promouvoir des appuis spécialisé dans plusieurs domaines d'intervention (psychologique, social et juridique), notamment à travers du partenariat avec la communauté locale et les institutions d'appui ; c) poursuivre avec l'amélioration des conditions d'accueil, en créant des salles d'accueil pour les victimes.

Mots-clés: Victime; violence conjugal; police.

\section{Pedido de separatas:}

LILIANA MARINHO

liliana.marinho1@gmail.com 